\title{
Does adherence to the World Cancer Research Fund/American Institute of Cancer Research cancer prevention guidelines reduce risk of colorectal cancer in the UK Women's Cohort Study?
}

\author{
Petra Jones ${ }^{1,2 *}$, Janet E. Cade ${ }^{1}$, Charlotte E. L. Evans ${ }^{1}$, Neil Hancock ${ }^{1}$ and Darren C. Greenwood ${ }^{1,3}$ \\ ${ }^{1}$ Nutritional Epidemiology Group, School of Food Science and Nutrition, University of Leeds, Leeds LS2 9JT, UK \\ ${ }^{2}$ Department of Food Sciences \& Nutrition, University of Malta, Msida MSD 2090, Malta \\ ${ }^{3}$ School of Medicine, Division of Epidemiology and Biostatistics, University of Leeds, Leeds LS2 9JT, UK \\ (Submitted 17 July 2017 - Final revision received 17 November 2017 - Accepted 4 December 2017-First published online 21 January 2018)
}

\section{Abstract}

Evidence on adherence to diet-related cancer prevention guidelines and associations with colorectal cancer (CRC) risk is limited and conflicting. The aim of this cohort analysis is to evaluate associations between adherence to the World Cancer Research Fund/American Institute of Cancer Research (WCRF/AICR) 2007 recommendations and incident CRC. The UK Women's Cohort Study comprises over 35372 women who filled in a FFQ at baseline in 1995. They were followed up for CRC incidence for a median of 17.4 years, an individual score linking adherence to eight of the WCRF/AICR recommendations was constructed. Cox proportional hazards regression provided hazard ratios (HR) and $95 \% \mathrm{CI}$ for the estimation of CRC risk, adjusting for confounders. Following exclusions, 444 CRC cases were identified. In the multivariate-adjusted model, women within the second and third (highest) categories of the WRCF/AICR score had HR of 0.79 (95\% CI 0.62 , $1.00)$ and 0.73 (95\% CI 0.48, 1.10), respectively, for CRC compared with those in the lowest, reference category. The overall linear trend across the categories was not significant $(P=0 \cdot 17)$. No significant associations were observed between the WCRF/AICR score and proximal colon, distal colon and rectal cancers separately. Of the individual score components, a BMI within the normal weight range was borderline significantly protective only for rectal cancer in the fully adjusted model. In view of the likely different causes of CRC subtypes, further research is needed to identify the optimal dietary patterns associated with reducing colon and rectal cancer risk, respectively.

Key words: World Cancer Research Fund/American Institute of Cancer Research guidelines: Colonic neoplasms: Rectal neoplasms: Nutritional epidemiology

Colorectal cancer (CRC) is the third most common cancer in men and the second in women, with about 694000 annual deaths estimated worldwide, accounting for $8.5 \%$ of deaths from cancer. With respect to incidence, almost $55 \%$ of cases are reported in the more developed countries and occurrence differs 10 -fold in both men and women, between countries ${ }^{(1)}$. This wide geographical variation in incidence supports the theory that diet and nutrition may have a role in the aetiology of $\mathrm{CRC}$ and are thus considered modifiable risk factors ${ }^{(2)}$.

Although the role of diet in relation to CRC risk has been widely investigated, the synergistic effect and complex interactions of food components make the analysis of dietary patterns better at capturing disease risk than individual foods or nutrients ${ }^{(3)}$. Furthermore, dietary data combined with data on lifestyle choices represents a more complete picture. Guidelines promoting lifestyles to reduce cancer risk have been issued by both the American Cancer Society $(\mathrm{ACS})^{(4)}$ and the World
Cancer Research Fund (WCRF) and the American Institute of Cancer Research (AICR) ${ }^{(5)}$. Both sets of guidelines include recommendations targeting a healthy diet and body weight, low alcohol consumption, if any, and more physical activity for cancer prevention whilst the WCRF/AICR also makes two special recommendations to encourage breast-feeding where possible and for cancer survivors to follow guidelines for cancer prevention $^{(5)}$. Several studies have operationalised a set of these guidelines to explore the association between concordance to the guidelines and reduced risk of chronic diseases, all-cause cancer and mortality ${ }^{(6-8)}$.

With respect to reduced risk of incidence of cancers of the colon and rectum, studies have mainly explored adherence to ACS guidelines $^{(9,10)}$ or the Dietary Guidelines for Americans ${ }^{(11)}$, and others have looked at incidence of total CRC rather than differentiated between the colon and rectal cancer-sites ${ }^{(12-15)}$. Furthermore, results of the latter studies are conflicting. Further studies

Abbreviations: AICR, American Institute of Cancer Research; CRC, colorectal cancer; EPIC, European Prospective Study Investigation into Cancer and Nutrition; HR, hazard ratio; UKWCS, UK Women's Cohort Study; VITAL, VITamins and Lifestyle; WCRF, World Cancer Research Fund.

* Corresponding author: P. Jones, email petra.jones@um.edu.mt 
operationalising the $\mathrm{WCRF} / \mathrm{AICR}$ guidelines and looking at the association between CRC, and exploring colon and rectal cancer separately are needed. In fact, the 2017 WCRF/AICR Continuous Update Project report stated that due to the limited evidence on this association, no conclusion can be made ${ }^{(16)}$.

The aim of this study is to assess whether adherence to the WCRF/AICR cancer prevention recommendations released in 2007, related to body fatness, physical activity, nutrition and breast-feeding is associated with reduced incidence of cancer of the colorectum, colon and rectum in a large UK cohort of women with a long follow-up period.

\section{Methods}

\section{Study design and population}

The UK Women's Cohort Study (UKWCS) of 35372 middle-aged women was formed from participants of a WCRF 1995 direct mail survey, targeted towards women, with the aim of exploring diet and chronic disease associations. Dietary information at baseline was obtained using a postal questionnaire between 1995 and 1998, including a FFQ as well as information on lifestyle and health. Participants with varied dietary patterns were chosen for inclusion in the cohort: namely large numbers of vegetarians, fish (non-meat) eaters and meat eaters. This maximisation in dietary variation increases the explorative power of the cohort with respect to diet and disease outcomes. The cohort women have a mean age of 52.3 (SD 9.4) years at baseline, are mainly middleclass and $86 \%$ have children. They are generally well-educated with $27 \%$ having a degree and health conscious with only $8 \%$ reporting that they smoke daily and a mean BMI in the normal range. Further details on the cohort profile have been reported in detail elsewhere ${ }^{(17,18)}$.

\section{Baseline characteristics and dietary information}

Values for age, weight, height and waist circumference were self-reported. Additional information on medical history, smoking habit, supplement use and breast-feeding was also self-described, as was socio-demographic information such as marital status. Participants were asked about the time spent on vigorous activities to collect information on physical activity whilst their socio-economic status was classified based on their occupation. Women were grouped as either (a) professional/ managerial; (b) intermediate; (c) routine/manual as defined by the UK National Statistics - Socio-Economic Classification ${ }^{(19)}$. Although collected, ethnicity data were not used as over $99 \%$ of cohort participants were Caucasian.

The FFQ sent to participants at baseline was developed from one used by the Oxford arm of the European Prospective Study Investigation into Cancer and Nutrition (EPIC) ${ }^{(20)}$, and adapted to better suit the high proportion of vegetarians in the UKWCS. A total of 217 food items made up the questionnaire; participants were asked to tick one of ten pre-coded categories, indicating average consumption frequency of the specific item over a 12-month period and ranging from never to six portions/d or more. The estimated number of portions were assigned a standard portion weight and the energy intake from macronutrients and alcohol was derived using McCance \& Widdowson's The Composition of Foods (5th edition) ${ }^{(21)}$. In the case of missing data on food consumption, non-response was assumed to imply non-consumption.

\section{Ethical approval}

Ethical approval was granted at the initiation of the UKWCS in 1995 from 174 individual relevant research ethics committees (REC) and from participants consenting to the confidential use of collected data at baseline, in follow-up stages and from cancer registries for research purposes. The REC reference no. is 15/YH/0027.

\section{Cancer case definition}

The cancer outcomes used in the analyses are incident malignant neoplasms of the colon (as identified by codes 153.0-153.9 or C18) and of the rectosigmoid junction and of the rectum (as identified by codes 154.0-154.1 or C19 and C20) of the International Statistical Classification of Diseases (9th and 10th revisions) $)^{(22,23)}$. Registrations of cancer diagnosis for women in the UKWCS were made via record linkage of identification codes to the central register of the National Health Service (NHS) Digital. This data is available from baseline in 1995 until the 1 April 2014 for $98 \%$ of the cohort women. Cases were defined as patients who were cancer free, except for non-melanoma skin cancer, at the time of FFQ completion and who developed CRC, as reported through the NHS Digital, a minimum of 12 months after the dietary assessment to ensure the absence of latent disease that may otherwise have influenced the women's dietary habits. In cases where no self-reported data of prior medical history was available ( $n$ 2585), women were assumed to be free from disease.

\section{World Cancer Research Fund/American Institute of Cancer} Research score construction

An adherence score to WCRF/AICR recommendations for cancer prevention was generated from the UKWCS database for each cohort participant. The approach taken in constructing the score was to operationalise eight out of ten WCRF/AICR recommendations, namely body fatness, physical activity, foods and drinks that promote weight gain, plant foods, animal foods, alcoholic drinks, consumption of salty foods and breast-feeding. All recommendations for which data was available were operationalised in an attempt to allow the evaluation of adherence to the dietary pattern formed as a whole, in relation to $\mathrm{CRC}$ risk. The recommendation to avoid the use of dietary supplements for cancer protection was explored in sensitivity analyses as data in the cohort related only to whether supplements were taken or not, and no information was available on whether supplements were taken to reduce cancer risk. The recommendation for cancer survivors was not applicable to this population.

A maximum adherence score of 8 was therefore possible for the UKWCS, with higher values indicating greater concordance with the recommendations. If the recommendation was met, the 
woman was assigned a score of 1 , if not met a 0 was assigned and an intermediate category for partially met, resulting in a score of 0.5 was also created. Each major recommendation contributed equally to the final single score for each participant as WCRF/AICR recommendations were not ranked according to priority. For guidelines with more than one sub recommendation, namely energy density and plant foods, each sub recommendation was scored separately and an average of the allocated scores was derived. Where quantitative criteria were described in the WCRF/AICR recommendations, these were used as cut-offs. This was the case for body fatness, physical activity, energy density, consumption of fruit and vegetables, dietary fibre intake, consumption of animal food, alcohol intake, $\mathrm{Na}$ intake and breast-feeding. With respect to the consumption of sugary drinks, the recommendation is avoidance of drinks with added sugars; for this study subjects were considered non-adherent if they reported consuming more than one sugary drink a day ( $>250 \mathrm{~g} / \mathrm{d}$ ) in the FFQ. Participants with missing data on BMI were dropped from the analysis, those with missing information on physical activity ( $n$ 1928) and breast-feeding ( $n$ 9533) were assumed to not have undertaken physical activity or breast-fed, respectively, whilst missing data on food and drinks was assumed to imply non-consumption. Details of the score operationalisation are given in Table 1. The WCRF/AICR scores for participants were categorised into three groups, to indicate low, medium and high adherence to the recommendations (i.e. $0-\leq 3,>3-\leq 5,>5-8$ ).

\section{Statistical analysis}

Descriptive statistics were used to describe baseline characteristics of participants. Survival analysis was conducted using the Cox proportional hazards regression model to estimate cancer risk in the form of hazard ratios (HR) and 95\% CI. The relationship between adherence to WCRF/AICR guidelines and CRC was explored as the primary outcome, whilst some exploratory analysis was carried out on distal and proximal colon cancers and on rectal cancer as secondary outcomes. Probability weighting was used to account for the large proportion of vegetarians and fish eaters in the cohort and to reflect the inverse probability of being sampled, thus increasing the cohort's external validity. The time variable used in the models was time in the study (person years), calculated from the date of questionnaire receipt until either cancer diagnosis, death or censor date (1 April 2014). Assumptions for proportional hazards were tested graphically for all terms in the model.

The risk of cancer as adherence to the WCRF/AICR score increased was determined by comparing each of the four groups of participants, to the lowest adherence, reference group. Risk estimates were calculated per one-point increment in the continuous WCRF/AICR score and by the score quartiles; linear trend was also calculated. Risk factors for CRC previously identified in the literature were taken into consideration. Potential confounders that were either included in the score derivation, such as BMI and physical activity, or were closely related to a score component, such as energy (kJ (kcal)) to energy density were excluded from the adjusted analyses, as were those that had considerable missing observations, particularly if a strongly related variable was available. Associations were estimated for CRC, and then for colon, proximal colon, distal colon and rectal cancer separately. Results are presented for an age-adjusted model, and then for a full model adjusting for age (years), smoking status (never, current or former smoker), family history in a first degree relative and socio-economic status (professional/managerial, intermediate or routine and manual). Sensitivity analyses were carried out operationalising a 9th recommendation relating to supplement use in the WCRF/AICR score (data not shown).

Stata version 13.0 statistical software was used for all analyses and a two-sided $P$-value $\leq 0.05$ was considered statistically significant.

\section{Results}

During a mean follow up time of 18.7 (SD 0.8) years, 527 incident CRC cases were documented for women in the UKWCS. From the total cohort ( $n$ 35372), participants who did not provide sufficient data at baseline to allow flagging on NHS Digital ( $n$ 695), women self-reporting history of any previous malignant cancer at baseline, except for non-melanoma of the skin ( $n$ 2391), women who were diagnosed with CRC within 1 year of baseline ( $n$ 53), women with energy intakes outside the plausible range of 500 to $6000 \mathrm{kcal} / \mathrm{d}$ (2092 to $25104 \mathrm{~kJ} / \mathrm{d}$ ) ( $n$ 79), and women with missing data for BMI ( $n$ 1191) were excluded. Following exclusions, a total of 30963 cohort participants, followed for a median of 17.4 years (interquartile range $=1.7$ ) were eligible for inclusion in the analysis with 444 CRC cases, of which 322 were located in the colon (164 in the proximal colon and 115 cases in the distal colon) and 146 cases were of rectal cancer.

The baseline characteristics of total study participants, women diagnosed with CRC and according to the level of adherence to the WCRF/AICR recommendations are reported in Table 2 . Women who were in the highest adherence category of the score were likely to be younger and less likely to smoke or eat meat when compared with those in low and medium adherence categories. Lower adherers were less likely to possess a degree qualification or to hold a managerial position.

The HR for incidence of colorectal, colon and rectal cancer according to the three different adherence categories of the WCRF/AICR score are shown in Table 3. In the age-adjusted model, those within the second and third adherence categories had HR for CRC of 0.76 (95\% CI 0.61, 0.95) and 0.66 (95\% CI $0.45,0.99)(P=0.05)$, respectively, compared with those in the lowest adherence category, with a one-unit increment in the WCRF/AICR score corresponding to a $10 \%$ decrease in risk of CRC $(\mathrm{HR}=0 \cdot 90,95 \% \mathrm{CI} 0 \cdot 81,1 \cdot 00)$. However, further adjustment for smoking, socio-economic status and family history of $\mathrm{CRC}$ in a first degree relative rendered the overall linear trend across the categories for the association non-statistically significant $(P=0 \cdot 17)$. Although HR suggested an inverse relationship between the WCRF/AICR score and cancers of the colon and rectum, respectively, no significant associations were observed in multivariate-adjusted models. Sensitivity analyses operationalising the recommendation for dietary supplements did not significantly change the results (data not shown). 


\section{Nos British Journal of Nutrition}

Table 1. Classification and operationalization of the World Cancer Research Fund/American Institute of Cancer Research (WCRF/AICR) cancer prevention recommendations and the percentage adherence in the UK Women's Cohort Study (UKWCS)

\begin{tabular}{|c|c|c|c|c|c|}
\hline WCRF/AICR recommendations & Personal recommendations & Operationalisation & Scoring & $\begin{array}{c}\text { UKWCS } \\
\text { adherents (\%) }\end{array}$ & $\begin{array}{l}\text { CRC cases } \\
\text { adherents (\%) }\end{array}$ \\
\hline \multirow[t]{4}{*}{$\begin{array}{l}\text { 1. Body fatness: be as lean as possible within the normal } \\
\text { range of body weight }\end{array}$} & $\begin{array}{l}\text { (a) Ensure that body weight through childhood and } \\
\text { adolescent growth projects towards the lower } \\
\text { end of the normal BMl range at } 21\end{array}$ & Insufficient data available & NA & NA & NA \\
\hline & \multirow{2}{*}{$\begin{array}{l}\text { (b) Maintain body weight within the normal range } \\
\text { from age } 21 \text { years }\end{array}$} & BMI: $18.5-24.9 \mathrm{~kg} / \mathrm{m}^{2}$ & 1 & $62 \cdot 4$ & $55 \cdot 6$ \\
\hline & & $\begin{array}{l}\text { BMl: } 25-29.9 \mathrm{~kg} / \mathrm{m}^{2} \\
\text { BMl: }<18.5 \text { or } \geq 30 \mathrm{~kg} / \mathrm{m}^{2}\end{array}$ & $\begin{array}{l}0.5 \\
0\end{array}$ & $\begin{array}{l}25 \cdot 6 \\
12 \cdot 0\end{array}$ & $\begin{array}{l}26 \cdot 8 \\
17 \cdot 6\end{array}$ \\
\hline & $\begin{array}{l}\text { (c) Avoid weight gain and increases in waist } \\
\text { circumference throughout adulthood }\end{array}$ & Insufficient data available & NA & NA & NA \\
\hline \multirow{3}{*}{$\begin{array}{l}\text { 2. Physical activity: be physically active as part of } \\
\text { everyday life }\end{array}$} & \multirow{2}{*}{$\begin{array}{l}\text { (a) Be moderately physically active, equivalent to } \\
\text { brisk walking, for } \geq 30 \text { min every day }\end{array}$} & $>30 \mathrm{~min} / \mathrm{d}$ of vigorous $\mathrm{PA}$ & 1 & $13 \cdot 8$ & $12 \cdot 6$ \\
\hline & & $\begin{array}{l}15-30 \mathrm{~min} / \mathrm{d} \text { of vigorous PA } \\
<15 \mathrm{~min} / \mathrm{d} \text { of vigorous PA } \\
\text { Insufficient data available }\end{array}$ & $\begin{array}{l}0.5 \\
0 \\
\text { NA }\end{array}$ & $\begin{array}{l}19 \cdot 4 \\
66 \cdot 8 \\
\text { NA }\end{array}$ & $\begin{array}{r}17 \cdot 1 \\
70 \cdot 3 \\
\text { NA }\end{array}$ \\
\hline & \multirow{3}{*}{ (a) Consume energy-dense foods sparingly } & $\begin{array}{l}\text { Insufficient data available } \\
\text { ED: }<125 \mathrm{kcal} / 100 \mathrm{~g} / \mathrm{d}\end{array}$ & NA & $\begin{array}{c}\text { NA } \\
32.8\end{array}$ & NA \\
\hline \multirow{5}{*}{$\begin{array}{l}\text { 3. Foods and beverages that promote weight gain: } \\
\text { limit consumption of energy-dense foods; avoid } \\
\text { sugary drinks }\end{array}$} & & ED: $>125-<175 \mathrm{kcal} / 100 \mathrm{~g} / \mathrm{d}$ & 0.5 & 57.9 & 59.0 \\
\hline & & ED: $>175 \mathrm{kcal} / 100 \mathrm{~g} / \mathrm{d}$ & 0 & $9 \cdot 3$ & 7.7 \\
\hline & \multirow[t]{3}{*}{ (b) Avoid sugary drinks } & Sugary drinks: $0 \mathrm{~g} / \mathrm{d}$ & 1 & 4.8 & $5 \cdot 2$ \\
\hline & & Sugary drinks: $\leq 250 \mathrm{~g} / \mathrm{d}$ & 0.5 & 83.5 & 84.0 \\
\hline & & Sugary drinks: $>250 \mathrm{~g} / \mathrm{d}$ & 0 & 11.7 & $10 \cdot 8$ \\
\hline \multirow{6}{*}{ 4. Plant foods: eat mostly foods of plant origin } & \multirow{2}{*}{$\begin{array}{l}\text { (a) Eat } \geq 5 \text { portions/servings }(\geq 400 \mathrm{~g} \text { ) of a variety of } \\
\text { non-starchy vegetables and of fruit every day }\end{array}$} & $\begin{array}{l}\text { Insufficient data available } \\
\text { F\&V: } \geq 400 \mathrm{~g} / \mathrm{d}\end{array}$ & $\begin{array}{l}\text { NA } \\
1\end{array}$ & $\begin{array}{c}\text { NA } \\
24.5\end{array}$ & 23.4 \\
\hline & & $\begin{array}{l}\text { F\&V: } 200-<400 \mathrm{~g} / \mathrm{d} \\
\text { F\&V: }<200 \mathrm{~g} / \mathrm{d}\end{array}$ & $\begin{array}{l}0.5 \\
0\end{array}$ & $\begin{array}{l}41 \cdot 1 \\
34.4\end{array}$ & $\begin{array}{l}42 \cdot 8 \\
33 \cdot 8\end{array}$ \\
\hline & \multirow{2}{*}{$\begin{array}{l}\text { (b) Eat relatively unprocessed cereals (grains) and/ } \\
\text { or pulses (legumes) with every meal }\end{array}$} & Dietary fibre: $\geq 25 \mathrm{~g}$ & 1 & 7.5 & $7 \cdot 0$ \\
\hline & & $\begin{array}{l}\text { Dietary fibre: } 12.5-<25 \mathrm{~g} / \mathrm{d} \\
\text { Dietary fibre: }<12.5 \mathrm{~g} / \mathrm{d}\end{array}$ & $\begin{array}{l}0.5 \\
0\end{array}$ & $\begin{array}{l}50 \cdot 4 \\
42 \cdot 1\end{array}$ & $\begin{array}{l}50 \cdot 2 \\
42 \cdot 8\end{array}$ \\
\hline & (c) Limit refined starchy foods & Insufficient data available & NA & NA & NA \\
\hline & $\begin{array}{l}\text { (d) People who consume starchy roots or tubers as } \\
\text { staples should also ensure sufficient intake or } \\
\text { non-starchy vegetables, fruit and pulses (legumes) }\end{array}$ & Not applicable to this population & NA & NA & NA \\
\hline \multirow{2}{*}{$\begin{array}{l}\text { 5. Animal foods: limit intake of red meat and avoid } \\
\text { processed meat }\end{array}$} & \multirow{2}{*}{$\begin{array}{l}\text { People who eat red meat should consume } \\
<500 \mathrm{~g} / \text { week and very few, if any, processed meats }\end{array}$} & $\mathrm{rpm}<500 \mathrm{~g} / \mathrm{week}$ and $\mathrm{PM}<3 \mathrm{~g} / \mathrm{d}$ & 1 & $36 \cdot 0$ & $27 \cdot 3$ \\
\hline & & $\begin{array}{l}\mathrm{rpm}<500 \mathrm{~g} / \text { week and PM } 3-<50 \mathrm{~g} / \mathrm{d} \\
\mathrm{rpm} \geq 500 \mathrm{~g} \text { or } \mathrm{PM} \geq 50 \mathrm{~g} / \mathrm{d}\end{array}$ & $\begin{array}{l}0.5 \\
0\end{array}$ & $\begin{array}{l}48 \cdot 8 \\
15 \cdot 2\end{array}$ & $\begin{array}{l}53 \cdot 8 \\
18 \cdot 9\end{array}$ \\
\hline \multirow[t]{2}{*}{ 6. Alcohol: limit alcoholic drinks } & \multirow{2}{*}{$\begin{array}{l}\text { If alcoholic drinks are consumed, limit consumption } \\
\text { to } \leq 2 \text { drinks/d for men and } 1 \text { drink/d for women }\end{array}$} & Ethanol: $\leq 10 \mathrm{~g} / \mathrm{d}$ & 1 & $66 \cdot 3$ & $68 \cdot 2$ \\
\hline & & $\begin{array}{l}\text { Ethanol: }>10-20 \mathrm{~g} / \mathrm{d} \\
\text { Ethanol: }>20 \mathrm{~g} / \mathrm{d}\end{array}$ & 0.5 & $\begin{array}{l}21 \cdot 1 \\
12.6\end{array}$ & $\begin{array}{l}19.4 \\
12.4\end{array}$ \\
\hline \multirow{4}{*}{$\begin{array}{l}\text { 7. Preservation, processing, preparation: limit consumption } \\
\text { of salt; avoid mouldy cereals (grains) or pulses (legumes) }\end{array}$} & \multirow{3}{*}{$\begin{array}{l}\text { (a) Avoid salt-preserved, salted or salty foods; } \\
\text { preserve foods without using salt } \\
\text { (b) Limit consumption of processed foods with added } \\
\text { salt to ensure an intake of }<6 \mathrm{~g}(2.4 \mathrm{~g} \mathrm{Na} \text { ) every day }\end{array}$} & Insufficient data available & NA & NA & NA \\
\hline & & $\mathrm{Na}: \leq 1.5 \mathrm{~g} / \mathrm{d}$ & 1 & $\begin{array}{r}3.5 \\
53 \cdot 3\end{array}$ & 3.36 \\
\hline & & $\begin{array}{l}\mathrm{Na}:>1.5-2.4 \mathrm{~g} / \mathrm{d} \\
\mathrm{Na}:>2.4 \mathrm{~g} / \mathrm{d}\end{array}$ & $\begin{array}{l}0.5 \\
0\end{array}$ & $\begin{array}{l}23 \cdot 3 \\
73 \cdot 2\end{array}$ & $\begin{array}{l}23 \cdot 2 \\
73 \cdot 2\end{array}$ \\
\hline & $\begin{array}{l}\text { (c) Do not eat mouldy cereals (grains) or pulses } \\
\text { (legumes) }\end{array}$ & Insufficient data available & NA & NA & NA \\
\hline $\begin{array}{l}\text { 8. Dietary supplements: aim to meet nutritional needs } \\
\text { through diet alone }\end{array}$ & $\begin{array}{l}\text { Dietary supplements are not recommended for } \\
\text { cancer prevention }\end{array}$ & Not applicable to this population & NA & NA & NA \\
\hline \multicolumn{6}{|l|}{ WCRF/AICR special recommendations } \\
\hline \multirow{2}{*}{$\begin{array}{l}\text { S1. Breast-feeding (BF): mothers to breast-feed; } \\
\text { children need to be breast-fed }\end{array}$} & \multirow{2}{*}{$\begin{array}{l}\text { Aim to breast-feed infants exclusively up to } \\
6 \text { months and continue with supplementary } \\
\text { feeding thereafter }\end{array}$} & Cumulative BF: $\geq 6$ months & 1 & 38.2 & 37.6 \\
\hline & & $\begin{array}{l}\text { Cumulative BF: }>0-<6 \text { months } \\
\text { No breast-feeding }\end{array}$ & $\begin{array}{l}0.5 \\
0\end{array}$ & $\begin{array}{l}26 \cdot 4 \\
35 \cdot 4\end{array}$ & $\begin{array}{l}28 \cdot 8 \\
33 \cdot 6\end{array}$ \\
\hline \multirow{2}{*}{$\begin{array}{l}\text { S2. Cancer survivors: follow the recommendations for } \\
\text { cancer prevention }\end{array}$} & \multirow{2}{*}{$\begin{array}{l}\text { (a) All cancer survivors should receive nutritional } \\
\text { care from an appropriately trained professional } \\
\text { (b) If able to do so, and unless otherwise advised, } \\
\text { aim to follow the recommendations for diet, } \\
\text { healthy weight, and physical activity }\end{array}$} & Not applicable to this population & NA & NA & NA \\
\hline & & Not applicable to this population & NA & NA & NA \\
\hline
\end{tabular}

NA, not applicable; PA, physical activity; ED, energy density; F\&V, fruit and vegetables; rpm, red and processed meat; PM, processed meat. 
Table 2. Characteristics of colorectal cancer (CRC) cases and across World Cancer Research Fund/American Institute of Cancer Research (WCRF/AICR) quartiles for participants in the UK Women's Cohort Study.

(Numbers and percentages; mean values and $95 \%$ confidence intervals; medians and interquartile ranges (IQR))

\begin{tabular}{|c|c|c|c|c|c|c|c|c|c|c|}
\hline \multirow[b]{3}{*}{ Variables } & & & & & \multicolumn{6}{|c|}{ WCRF/AICR score categories } \\
\hline & \multicolumn{2}{|c|}{ Total } & \multicolumn{2}{|c|}{ CRC cases } & \multicolumn{2}{|c|}{1} & \multicolumn{2}{|c|}{2} & \multicolumn{2}{|c|}{3} \\
\hline & $n$ & $\%$ & $n$ & $\%$ & $n$ & $\%$ & $n$ & $\%$ & $n$ & $\%$ \\
\hline Observations & \multirow{2}{*}{\multicolumn{2}{|c|}{30963}} & 444 & 1.4 & 6319 & $20 \cdot 4$ & 20978 & $67 \cdot 7$ & 3671 & 11.9 \\
\hline WCRF/AICR score range & & & & & \multicolumn{2}{|c|}{$0-3$} & \multicolumn{2}{|c|}{$3.25-5$} & \multirow{2}{*}{\multicolumn{2}{|c|}{$5 \cdot 25-8.0$}} \\
\hline \multicolumn{9}{|l|}{ Age (years) } & & \\
\hline Mean & \multirow{2}{*}{\multicolumn{2}{|c|}{$\begin{array}{c}52 \cdot 0 \\
51 \cdot 9,52 \cdot 1\end{array}$}} & \multirow{2}{*}{\multicolumn{2}{|c|}{$\begin{array}{c}57 \cdot 7 \\
56 \cdot 9,58 \cdot 6\end{array}$}} & \multirow{2}{*}{\multicolumn{2}{|c|}{$\begin{array}{c}52 \cdot 8 \\
52 \cdot 6,53 \cdot 0\end{array}$}} & \multirow{2}{*}{\multicolumn{2}{|c|}{$\begin{array}{c}52 \\
51 \cdot 9,52 \cdot 1\end{array}$}} & \multirow{2}{*}{\multicolumn{2}{|c|}{$50 \cdot 6$}} \\
\hline $95 \% \mathrm{Cl}$ & & & & & & & & & & \\
\hline \multicolumn{11}{|l|}{$\mathrm{BMI}\left(\mathrm{kg} / \mathrm{m}^{2}\right)$} \\
\hline Mean & \multirow{2}{*}{\multicolumn{2}{|c|}{$\begin{array}{c}24 \cdot 4 \\
24 \cdot 4,24 \cdot 5\end{array}$}} & \multirow{2}{*}{\multicolumn{2}{|c|}{$\begin{array}{c}25 \cdot 1 \\
24 \cdot 6.25 \cdot 5\end{array}$}} & \multirow{2}{*}{\multicolumn{2}{|c|}{$\begin{array}{c}26 \cdot 9 \\
26 \cdot 8,27 \cdot 0\end{array}$}} & \multirow{2}{*}{\multicolumn{2}{|c|}{$\begin{array}{c}24 \\
24 \cdot 0.24 \cdot 1\end{array}$}} & \multirow{2}{*}{\multicolumn{2}{|c|}{$\begin{array}{c}22.5 \\
22.4 .22 .5\end{array}$}} \\
\hline $95 \% \mathrm{Cl}$ & & & & & & & & & & \\
\hline Energy intake (kcal/d) & & & & & & & & & & \\
\hline Mean & & & & & & & & & & \\
\hline $95 \% \mathrm{Cl}$ & & & & & & & 231 & & & \\
\hline Energy intake $(\mathrm{kJ} / \mathrm{d})$ & & & & & & & & & & \\
\hline Mean & & & & & & & & & & \\
\hline $95 \% \mathrm{Cl}$ & & & & & & & 969 & & & \\
\hline Ethanol $(\mathrm{g} / \mathrm{d})$ & & & & & & & & & & \\
\hline Median & & & & & & & & & & \\
\hline IQR & & & & & & & & & & \\
\hline Physical activity (h/d) & & & & & & & & & & \\
\hline Mean & & & & & & & & & & \\
\hline $95 \% \mathrm{Cl}$ & & & & & & & & & & \\
\hline Smoking status & & & & & & & & & & \\
\hline Current smoker & 3361 & $11 \cdot 2$ & 42 & 9.8 & 985 & $16 \cdot 0$ & 2106 & $10 \cdot 3$ & 270 & 7.6 \\
\hline Former smoker & 9240 & $30 \cdot 7$ & 136 & 31.6 & 2006 & 32.5 & 6146 & $30 \cdot 2$ & 1088 & 30.6 \\
\hline Never smoker & 17501 & 58.14 & 252 & 58.6 & 3177 & 51.5 & 12129 & 59.5 & 2195 & 61.8 \\
\hline Socio-economic status & & & & & & & & & & \\
\hline Professional/managerial & 19298 & $63 \cdot 6$ & 247 & $57 \cdot 0$ & 3688 & $59 \cdot 6$ & 13039 & 63.5 & 2571 & 71.5 \\
\hline Intermediate & 8298 & $27 \cdot 4$ & 139 & $32 \cdot 1$ & 1825 & 29.5 & 5734 & $27 \cdot 9$ & 739 & 20.5 \\
\hline Routine and manual & 2736 & 9.0 & 47 & $10 \cdot 9$ & 675 & 10.9 & 1773 & 8.6 & 288 & 8.0 \\
\hline Education level & & & & & & & & & & \\
\hline No qualifications & 4656 & $16 \cdot 4$ & 98 & 24.8 & 1215 & $21 \cdot 2$ & 3020 & $15 \cdot 7$ & 421 & $12 \cdot 2$ \\
\hline Non-degree qualifications & 15983 & $56 \cdot 2$ & 205 & $51 \cdot 8$ & 3209 & 55.9 & 10920 & $56 \cdot 8$ & 1854 & 53.6 \\
\hline Degree & 7789 & 27.4 & 93 & 23.5 & 1312 & 22.9 & 5293 & 27.5 & 1184 & 34.2 \\
\hline Diet group & & & & & & & & & & \\
\hline Meat eaters & 19919 & $70 \cdot 3$ & 317 & 78.5 & 5162 & $92 \cdot 2$ & 13408 & $69 \cdot 8$ & 1349 & 38.3 \\
\hline Fish eaters & 3860 & $13 \cdot 6$ & 39 & 9.7 & 181 & 3.2 & 2699 & $14 \cdot 1$ & 980 & $27 \cdot 8$ \\
\hline Vegetarians & 4543 & $16 \cdot 0$ & 48 & 11.9 & 254 & 4.5 & 3095 & $16 \cdot 1$ & 1194 & 33.9 \\
\hline Supplement users & 16244 & 57.6 & 236 & $58 \cdot 3$ & 2972 & $51 \cdot 2$ & 11129 & $58 \cdot 3$ & 2143 & $65 \cdot 3$ \\
\hline Family history of colorectal cancer & 1755 & 6.0 & 35 & $8 \cdot 3$ & 326 & 5.5 & 1238 & $6 \cdot 3$ & 191 & 5.6 \\
\hline
\end{tabular}


Table 3. Incidence of colorectal, colon and rectal cancer according to quartiles of the World Cancer Research Fund/American Institute of Cancer Research (WCRF/AICR) score.

(Hazard ratios (HR) and $95 \%$ confidence intervals)

\begin{tabular}{|c|c|c|c|c|c|c|}
\hline Cancer sites & WCRF/AICR score categories & Cases $^{*}$ & Age-adjusted HR & $95 \% \mathrm{Cl}$ & Multivariable-adjusted† HR & $95 \% \mathrm{Cl}$ \\
\hline \multirow[t]{6}{*}{ Colorectal } & & 444 & & & & \\
\hline & 1 & & 1.0 & & $1 \cdot 0$ & \\
\hline & 2 & & 0.76 & $0.61,0.95$ & 0.79 & $0.62,1.00$ \\
\hline & 3 & & 0.66 & $0.45,0.99$ & 0.73 & $0.48,1.10$ \\
\hline & Per 1 unit increment & & 0.90 & $0.81,1.00$ & 0.92 & $0.82,1.03$ \\
\hline & $P_{\text {trend }}$ & & 0.046 & & 0.169 & \\
\hline \multirow[t]{6}{*}{ Colon } & & 322 & & & & \\
\hline & 1 & & 1.0 & & 1.0 & \\
\hline & 2 & & 0.79 & $0.61,1.02$ & 0.82 & $0.62,1.09$ \\
\hline & 3 & & 0.61 & $0.38,0.99$ & 0.72 & $0.44,1.19$ \\
\hline & Per 1 unit increment & & 0.89 & $0.79,1.01$ & 0.93 & $0.82,1.07$ \\
\hline & $P_{\text {trend }}$ & & 0.065 & & 0.308 & \\
\hline \multirow[t]{6}{*}{ Proximal colon } & & 164 & & & & \\
\hline & 1 & & 1.0 & & 1.0 & \\
\hline & 2 & & 0.71 & $0.50,1.02$ & 0.75 & $0.51,1 \cdot 10$ \\
\hline & 3 & & 0.69 & $0.36,1.31$ & 0.83 & $0.43,1.60$ \\
\hline & Per 1 unit increment & & 0.90 & $0.76,1.06$ & 0.93 & $0.77,1.12$ \\
\hline & $P_{\text {trend }}$ & & 0.212 & & 0.441 & \\
\hline \multirow[t]{6}{*}{ Distal colon } & & 115 & & & & \\
\hline & 1 & & 1.0 & & 1.0 & \\
\hline & 2 & & 1.01 & $0.65,1.59$ & 0.96 & $0.58,1.58$ \\
\hline & 3 & & 0.41 & $0.17,0.99$ & 0.41 & $0.16,1.07$ \\
\hline & Per 1 unit increment & & 0.91 & $0.76,1.09$ & 0.93 & $0.76,1.14$ \\
\hline & $P_{\text {trend }}$ & & 0.290 & & 0.504 & \\
\hline \multirow[t]{6}{*}{ Rectal } & & 146 & & & & \\
\hline & 1 & & 1.0 & & 1.0 & \\
\hline & 2 & & 0.72 & $0.49,1.06$ & 0.72 & $0.48,1.08$ \\
\hline & 3 & & 0.65 & $0.33,1.28$ & 0.61 & $0.29,1.26$ \\
\hline & Per 1 unit increment & & 0.90 & $0.75,1.09$ & 0.88 & $0.72,1.08$ \\
\hline & $P_{\text {trend }}$ & & 0.291 & & 0.239 & \\
\hline
\end{tabular}

* Case numbers apply to multivariable-adjusted models.

† Adjusted for age, smoking status, socio-economic status and family history of colorectal cancer.

Table 4 shows the results for the independent association between the separate components of the WCRF/AICR score and risk of colorectal, colon and rectal cancer. In the age-adjusted models, women who met the recommendation for body fatness had a statistically significant reduced risk of colorectal and rectal cancer (HR 0.69; 95\% CI 0.53, 0.91; $P=0.03$ and HR 0.53; $95 \%$ CI $0.33,0.83 ; P=0.004)$, respectively, compared with those who did not. Women who met the recommendation for animal foods had a statistically significant $32 \%$ reduced risk of colon cancer incidence when compared with the non-adherent (HR $0.68 ; 95 \%$ CI $0.48,0.96 ; P=0.03$ ). These associations were however attenuated; the association between body fatness and rectal cancer did not reach statistical significance $(P=0.07)$, associations were not statistically significant for any of the other components in the fully adjusted multivariate models.

\section{Discussion}

This study evaluated adherence to the WCRF/AICR cancer prevention recommendations in relation to risk of CRC in a UK cohort of middle-aged women. The overall score related to operationalisation of eight recommendations was not significantly associated with incidence of colorectal, colon or rectal cancer in multivariate-adjusted analyses. Investigation of the separate score components showed adherence to the body fatness and animal foods recommendations to potentially offer a degree of protection against risk of cancers of the colorectum and rectum and of the colon, respectively.

Few studies have looked at the WCRF/AICR recommendations and CRC incidence. Findings from this study are consistent with those from the Framingham Offspring cohort ${ }^{(12)}$ and in the Black Women's Health Study ${ }^{(15)}$ where the overall WCRF/AICR score was not significantly associated with CRC incidence. Conversely, a one-point increment in the WCRF/AICR score was significantly associated with a $12 \%(95 \%$ CI 9,16$)$ decreased CRC risk in the EPIC cohort ${ }^{(13)}$ and a $13 \%(95 \%$ CI 5,20$)$ decreased risk of CRC in the VITamins and Lifestyle (VITAL) cohort $^{(14)}$. However, the EPIC and VITAL cohorts ${ }^{(13,14)}$ operationalised a total of seven and six recommendations, respectively, rather than eight score components as operationalised in this cohort. Notwithstanding, an evaluation of our results using a similar composite to the EPIC and VITAL cohorts ${ }^{(13,14)}$ to facilitate comparison, by dropping first the recommendation in relation to salt-preserved food, and second dropping two recommendations - those related to salt-preserved food and to breast-feeding, did not significantly change the results (data not shown). Thomson et $a$ al $^{\left({ }^{(9)}\right.}$ also reported a statistically significant decreased risk of CRC in the Women's Health Initiative Observational Study but the ACS cancer prevention guidelines were operationalised for the study and associations were weakest amongst whites, which may partly explain the inconsistency in findings when 
Table 4. Colorectal, colon and rectal cancers per component of the World Cancer Research Fund/American Institute of Cancer Research (WCRF/AICR) score. (Hazard ratios (HR) and 95\% confidence intervals)

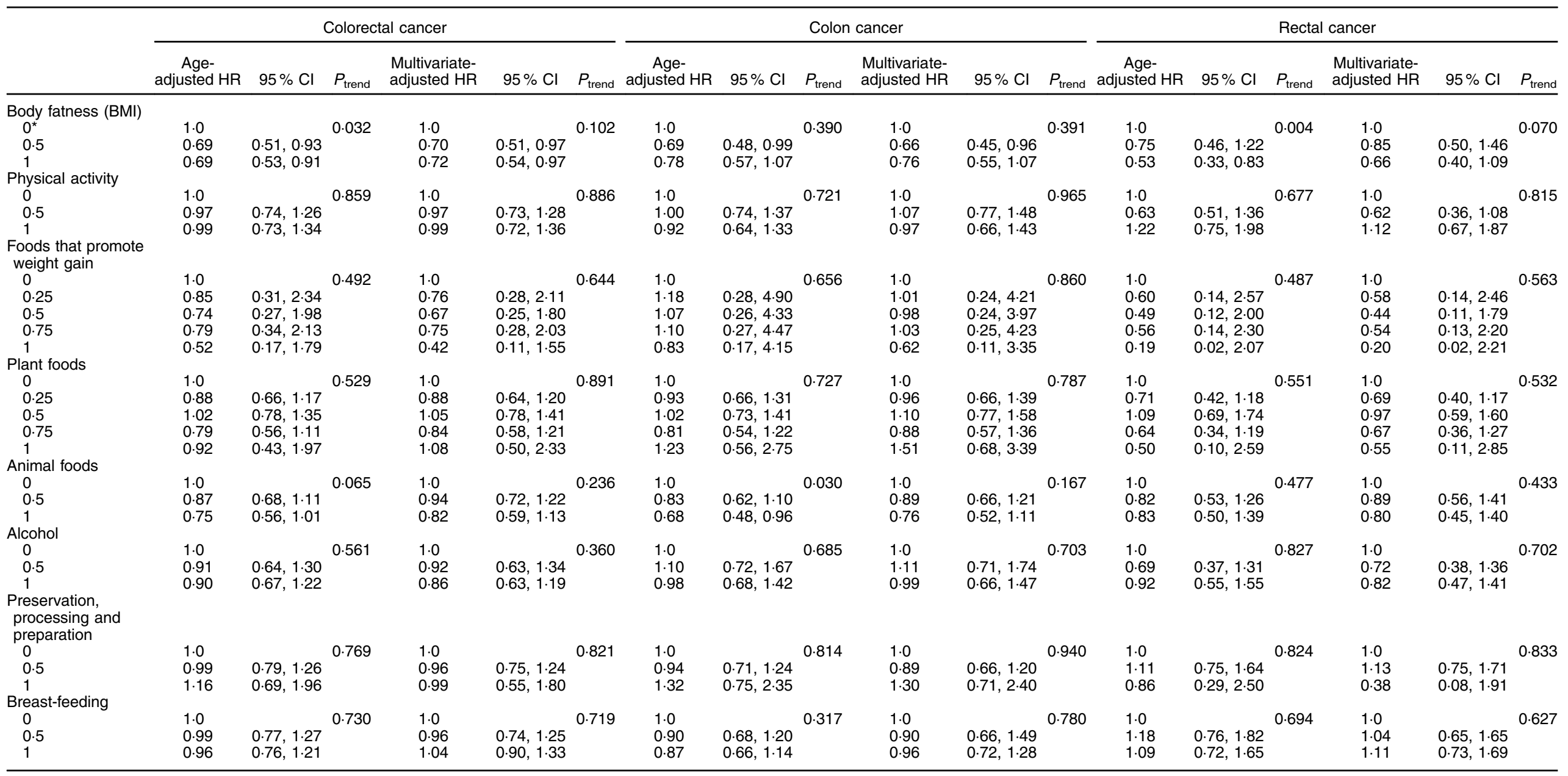

* 0 is assigned if the recommendation is not met, 0.5 is assigned for partly met recommendations and 1 is assigned for met recommendations. 
compared with this study where most women are white. Associations for colon and rectal cancers were not investigated separately in any of the previous cohort studies operationalising the WCRF/AICR guidelines. Two studies evaluating associations for risk of colon and rectal cancer separately looked at adherence to the Dietary Guidelines for Americans ${ }^{(11)}$ and to the ACS recommendations ${ }^{(4)}$, respectively. A statistically significant decrease in colon cancer risk was reported with greater adherence in both studies ${ }^{(10,11)}$. In agreement with results from this cohort, data from the Iowa Women's Health Study, a population-based cohort of postmenopausal women reported inverse, but not significant decreased rectal cancer incidence with increased adherence to cancer prevention guidelines ${ }^{(11)}$.

The different strengths of associations for the colon and for the rectal cancer sites may be due to the different biological characteristics of the mucosa in that part of the colorectum or to the different mechanisms in oncogenesis ${ }^{(24)}$. Notwithstanding this plausible explanation, the estimation of the association between the WCRF/AICR recommendations and cancer incidence by site should be considered as being of an exploratory nature due to the smaller sample size. The cohort comprises relatively health conscious women when compared with the general population. Furthermore, the source of diet assessment was a single FFQ measured at baseline that is not only prone to recall bias and under-reporting, but also may not be fully representative of eating patterns long term. Nevertheless, dietary patterns in the UKWCS have been previously shown to be relatively stable over time and using groupings of dietary patterns in contrast to energy and nutrient intake, reduces bias caused by such measurement error ${ }^{(25)}$. Although women who died within 1 year of dietary assessment were excluded to reduce reverse causation, anthropometric and lifestyle factors were self-reported, there is no data on their validity and thus potentially contributed to measurement error. No data were available on whether women were previously screened for CRC; this would have been an important confounding factor. These factors may have led to an attenuation of results suggesting that the association between risk of cancer at different sites of the colorectum and some dietary factors is probably stronger than stated in this cohort. Further discrepancies in results between different studies may be explained by differences in the treatment of the individual recommendations, the cut-offs chosen and the number of components used during the WCRF/AICR score operationalisation.

An assessment of the contribution of the individual components to the overall score showed body fatness, assessed by BMI to be the strongest predictor of cancer of both the colon and rectum, as well as animal foods being a predictor of colon cancer. This is in line with findings from the VITAL cohort ${ }^{(14)}$ who also reported body fatness and red and processed meat intake to be the recommendations most strongly associated with higher CRC risk for women. Despite inverse associations of these components with cancer incidence in this cohort, associations after adjusting for confounders were not significant although borderline significance was noted for BMI and rectal cancer. BMI was similarly reported to be the strongest predictor of all cancer incidence in the NIH_AARP cohort $^{(10)}$ whilst almost all components of the WCRF/AICR score were associated with total cancer incidence in the EPIC study ${ }^{(13)}$. The lack of statistical significance in this study with respect to BMI and animal foods could be explained by insufficient statistical power of the sample, or in the case of BMI, closely related measurements such as that of visceral fat may have been a better indicator of body fatness and a better predictor of $\mathrm{CRC}^{(26)}$. The association may also be stronger in men than in women, which could potentially explain the stronger links reported in other cohorts including both sexes ${ }^{(10,13)}$. Men have higher rates of CRC than women, with rectal cancer being higher in men and proximal colon cancer higher in women. Hormonal factors could protect women from distal cancers ${ }^{(27)}$. Other score components - such as breast-feeding, are unlikely to be on the direct causal pathway for cancer of the colorectum and thus, the fact that the scoring system used gives equal weighting to every recommendation is considered a limitation of this study.

Although the exact mechanisms linking body fatness to CRC are yet unclear, some possibilities have been put forward. Insulin/insulin-like growth factor (IGF) and the adipokines, adiponectin and leptin are two hormonal systems that have been hypothesised to mediate the association ${ }^{(28)}$. Adipose tissue is metabolically active and could produce inflammatory molecules that modulate carcinogenesis - cytokines, sex steroids and adipokines $^{(29)}$. Thus, as adiposity increases, concentrations of IGF-binding protein-1 and adiponectin decrease, resulting in elevated levels of free IGF-1 and serum leptin that have been associated with increased CRC risk ${ }^{(26)}$.

Strengths of this prospective cohort include its design, the long follow-up period, the potential to adjust for several confounding variables and the size of the study population. The latter enabled for the first time, a separate investigation of the colon and rectal sites in relation to the score derived from the WCRF/AICR cancer prevention guidelines and its individual components.

In conclusion, there were no statistically significant trends shown between adherence to the WCRF/AICR cancer prevention guidelines and risk of CRC. Of the individual score components, a BMI within the normal weight range was borderline significantly protective in the fully adjusted model, emphasising the importance of this for cancer prevention. A better understanding of different dietary components on this health outcome may permit higher or lower WCRF/AICR score component weighting. In view of the likely different causes of CRC subtypes, further research is needed to identify the optimal dietary patterns associated with reducing colon and rectal cancer risk, respectively.

\section{Acknowledgements}

The authors thank the women who took part in the UKWCS.

The UKWCS was originally funded by the World Cancer Research Fund. This work was supported by a scholarship from the University of Malta. The World Cancer Research Fund and the University of Malta had no role in the design, analysis or writing of this article.

J. E. C. conceived and designed the UKWCS, which was at its conception funded by the World Cancer Research Fund. P. J. conducted the analysis for this report, wrote the first version 
and contributed to all other versions. D. C. G. provided statistical advice. All authors contributed to the interpretation of the data and review of the manuscript.

J. E. C. is the director of a University company, Dietary Assessment Ltd.

\section{References}

1. Ferlay J, Soerjomataram I, Ervik M, et al. (2012) Cancer incidence and mortality worldwide: sources, methods and major patterns in GLOBOCAN. Int J Cancer 2013 136, E359-E386.

2. Center MM, Jemal A, Smith RA, et al. (2009) Worldwide variations in colorectal cancer. CA Cancer J Clin 59, 366-378.

3. Ocké MC (2013) Evaluation of methodologies for assessing the overall diet: dietary quality scores and dietary pattern analysis. Proc Nutr Soc 72, 191-199.

4. Kushi LH, Byers T, Doyle C, et al. (2006) American Cancer Society Guidelines on Nutrition and Physical Activity for cancer prevention: reducing the risk of cancer with healthy food choices and physical activity. CA Cancer J Clin 56, 254-281.

5. World Cancer Research Fund \& American Institute for Cancer Research (2007) Food, Nutrition, Physical Activity, and the Prevention of Cancer: A Global Perspective. Washington, DC: World Cancer Research Fund/American Institute for Cancer Research.

6. Cerhan JR, Potter JD, Gilmore JM, et al. (2004) Adherence to the AICR cancer prevention recommendations and subsequent morbidity and mortality in the Iowa Women's Health Study cohort. Cancer Epidemiol Biomarkers Prev 13, 1114-1120.

7. Inoue-Choi M, Lazovich D, Prizment AE, et al. (2013) Adherence to the World Cancer Research Fund/American Institute for Cancer Research recommendations for cancer prevention is associated with better health-related quality of life among elderly female cancer survivors. J Clin Oncol 31, 1758-1766.

8. Vergnaud AC, Romaguera D, Peeters PH, et al. (2013) Adherence to the World Cancer Research Fund/American Institute for Cancer Research guidelines and risk of death in Europe: results from the European Prospective Investigation into Nutrition and Cancer cohort study. Am J Clin Nutr 97, 1107-1120.

9. Thomson CA, McCullough ML, Wertheim BC, et al. (2014) Nutrition and physical activity cancer prevention guidelines, cancer risk, and mortality in the Women's Health Initiative. Cancer Prev Res 7, 42-53.

10. Kabat GC, Matthews CE, Kamensky V, et al. (2015) Adherence to cancer prevention guidelines and cancer incidence, cancer mortality, and total mortality: a prospective cohort study. Am J Clin Nutr (Epublication ahead of print version 7 January 2015).

11. Harnack L, Nicodemus K, Jacobs DR, et al. (2002) An evaluation of the Dietary Guidelines for Americans in relation to cancer occurrence. Am J Clin Nutr 76, 889-896.

12. Makarem N, Lin Y, Bandera EV, et al. (2015) Concordance with World Cancer Research Fund/American Institute for Cancer Research (WCRF/AICR) guidelines for cancer prevention and obesity-related cancer risk in the Framingham Offspring cohort (1991-2008). Cancer Causes Control 26, 277-286.
13. Romaguera D, Vergnaud AC, Peeters PH, et al. (2012) Is concordance with World Cancer Research Fund/American Institute for Cancer Research guidelines for cancer prevention related to subsequent risk of cancer? Results from the EPIC study. Am J Clin Nutr 96, 150-163.

14. Hastert TA \& White E (2016) Association between meeting the WCRF/AICR cancer prevention recommendations and colorectal cancer incidence: results from the VITAL cohort. Cancer Causes Control 27, 1347-1359.

15. Nomura SJ, Dash C, Rosenberg L, et al. (2016) Is adherence to diet, physical activity, and body weight cancer prevention recommendations associated with colorectal cancer incidence in African American women? Cancer Causes Control 27, 869-879.

16. World Cancer Research Fund \& American Institute for Cancer Research (2017) Continuous update project report: diet, nutrition, physical activity, and colorectal cancer. wcrf.org/ colorectal-cancer-2017 (accessed November 2017).

17. Cade JE, Burley VJ \& Greenwood DC (2004) The UK Women's Cohort Study: comparison of vegetarians, fish-eaters and meat-eaters. Public Health Nutr 7, 871-878.

18. Cade JE, Burley VJ, Alwan NA, et al. (2015) Cohort profile: the UK Women's Cohort Study (UKWCS). Int J Epidemiol 46, E11.

19. Rose D, Pevalin DJ \& O'Reilly K (2005) The National Statistics Socio-economic Classification: Origins, Development and Use. Basingstoke: Palgrave Macmillan.

20. Riboli E \& Kaaks R (1997) The EPIC Project: rationale and study design. European Prospective Investigation into Cancer and Nutrition. Int J Epidemiol 26, Suppl. 1, S6.

21. Holland B, Welch AA, Unwin ID, et al. (1991) McCance and Widdowson's The Composition of Foods. Cambridge: Royal Chemistry Society and Ministry of Agriculture, Fisheries and Food.

22. American Medical Association (2004) International Classification of Diseases, 9th Revision, Clinical Modification: Physician ICD-9-CM, 2005: Volumes 1 and 2, Color-Coded, Illustrated. Chicago, IL: American Medical Association.

23. World Health Organization (2008) International statistical classification of diseases and health related problems (The) ICD-10. Doctoral dissertation, World Health Organization.

24. Kapiteijn E, Liefers GJ, Los LC, et al. (2001) Mechanisms of oncogenesis in colon versus rectal cancer. J Pathol 195, $171-178$.

25. Greenwood DC, Gilthorpe MS, Golding C, et al. (2003) Stability over time of dietary patterns in the UK Women's Cohort Study. Proc Nutr Soc 62, 89A.

26. Larsson SC \& Wolk A (2007) Obesity and colon and rectal cancer risk: a meta-analysis of prospective studies. Am J Clin Nutr 86, 556-565.

27. Gao RN, Neutel CI \& Wai E (2008) Gender differences in colorectal cancer incidence, mortality, hospitalizations and surgical procedures in Canada. J Public Health 30, 194-201.

28. Ma Y, Yang Y, Wang F, et al. (2013) Obesity and risk of colorectal cancer: a systematic review of prospective studies. PLOS ONE 8, E53916.

29. Song M, Garrett WS \& Chan AT (2015) Nutrients, foods, and colorectal cancer prevention. Gastroenterology 148, $1244-1260$. 